the consideration of $\mathrm{Mr}$. Mallet's experiments on cooling slag run from an iron furnace. ${ }^{1}$

This coefficient is somewhat larger than the mean of those obtained by Mr. Adie ${ }^{2}$ for much lower temperatures. The mean of six of his values, half of thein being for moist rock and half for dry, I find to be 0000057 .

Mr. Darwin recalls attention to M. Favre's experiments (out of which the present correspondence arose). M. Favre's experiments illustrate well the structure of an alpine district. But I would observe that, if ours is a cooling solid globe, and if that would give rise to such surface structure, we ought to find it everywhere, and not confined to definite geographical areas, as we do.

Harlton, Cambridge, February 8

\section{Concerning the Colour of Eyes}

MAY a portrait painter be allowed to remark that there are two kinds of green eyes, and the poets have duly appreciated both. The eye of the "green-eyed monster" is, no doubt, the cold grey, or stony blue eye, overspread with the yellow of biliousness, hence green; but when Dante called the eyes of the beatified Beatrice emeralds he did not mean to insult her. The image called up by his ecstatic words is that of those deep, soft eyes which are $a$ warm brown in some lights-for instance with the light falling on them from one side only-and take a grey tint when facing the light of the sky, and green tints at other times, according to the lights that fall upon them; and are therefore sometimes a puzzle to portrait painters. Eyes, like the sea and precious stones, catch lights and transmute them. The sea is only green from the meeting of sunlight and blue sky light in it. J. M. H.

P.S.-Has it been remarked that the distinction between yellow and blue tints-the only one made by the colour-blind, according to Dr. Pole-is precisely the same as that made by the sun in photography : all the warm tints (as an artist-who makes the same distinction-would call those partaking of yellow) coming out darker, and all the cold ones-or those partaking of blue-lighter than in the object photographed?

\section{Intellect in Brutes}

A CORRESPONDENT in NATURE, vol, xix. p. 268, describes the actions of a water-rat which, he says, climbed up to a window-sill, inconvenient of access, and thirteen feet from the ground, in order to get some bread which was habitually put there for the birds during the cold weather. As the rat had never found food there befure, the writer concludes that his conduct cannot be attributed either to instinct or to experience, but must be ascribed to a process of reasoning based on the observation of the flocking together of the birds, and the inference that they must be attracted by food. Now it seems to me that before we ascribe to a rat such complicated reasonin powers it is necessary to ask if there is no other, simpler, way of accounting for the phenomenon. I think there is. It is well known that different species of animals vary greatly in the acuteness of their senses. To man, sight is the most important sense, and the same is true of many other animals, and most birds. The cat is a representative of another, smaller, class of animals, whose most perfect organ of sense is the ear; while the dog lives in a world of sensations, the most important of which are contributed by the sense of smell. To this last class bel ngs the rat, which is noted for the acuteness of its scent. It is evident, therefore, that the water-rat in question was led to the windowsill by his nose, which, in his case, was a more trustworthy guide than his eyes would have been. I do not wish to deny, by any means, that animals have reasoning powers. On the contrary, I am convinced that human and brute intellect differ only in degree, not in kind; and I even adopt Haeckel's "cellular psychology," which attributes the elements of intellectual life-sensation and volition-to infusoria and organic cells in general, in opposition to the older "neural psychology," according to which psychic activity begins with the nervous system in the scale of animal life. But what we have to guard against is not to ascribe to animals reasoning powers of a higher type than is consistent with the develapment of their brain, especially when the actions which seem to postulate such powers can be readily accounted for by simply bearing in mind the extraordinary acuteness of one

I Trans. Roy. Soz., paper read June 20, 1872 .

2 Trans. Roy. Soc. Edin., vol. xiii. F'. 370. or more of their senses. We are altogether too prone to judge the intellectual life of animals by the human standard, to imagine that the eye is everywhere, as with us, the leading source of knowledge; and the neglect of the important rôle which the sense of smell plays in animal life has been particularly fruitful of errors in philosophical speculation. It has, among other things, helped to give a longer base of life to the old theory of instinct, regarded as a mysterious power of nature.

Berlin, February 8

HENRY T. FINCK

\section{Ear Affection}

THE remarkable phenomenon described by your correspondent " $P$," in NATURE, vol. xix. p. 315, induces me to bring to your notice that precisely the same effect was produced in my own case a month ago, when partial deafness came on in both my ears, whilst suffering from congestion of the mucous membrane of the nasal passage and eustachian tube. Not being aware that any prior case had occurred of a distinct difference of a semitone, as indicated by the alternate application of a tuningfork to the two ears, I at once drew up a memorandum on the subject, and handed it to Dr. Urban Pritchard, who was advising me, Like your correspondent " $\mathrm{P}$," I have also noticed the double sound produced when I whistle, and more particularly when I close both ears with my fingers. G. L. WALLICH

February 11

\section{Bees' Stings}

THE American Quarterly Microscopical fournal, published last October in New York, contains an elaborate article on "The Sting of the Honey Bee," by J. D. Hyatt. Mr. Hyatt's experience does not tally with that of your correspondent, R. A. He says: "By allowing the bee to sting a soft piece of leather an excellent opportunity is offered for studying the action and mechanism, for the whole apparatus will be beautifully dissected, the bee not appearing to be seriously injured by the loss." I should be happy to send the journal to R. A. if I knew his address.

Sidmouth

W. RADFORD

\section{Electric Lighting}

I NOTICE in an article in NATURE, vol, xix. p. 262, the fol lowing reference made to our electric light that it "does not appear to give very great satisfation through its fluctuation." It is true that at first we were caused some trouble owing to the Serrin lamp not working properly, but having overcome the difficulty we find it in our business, where it is necessary to show colours correctly, a very great improvement on all our former trials of lighting, and moreover, in its use we are not troubled in our galleries and upper floors with the heat and fumes which with gas alight no amount of ventilation seemed to remove.

It is not a pleasant light to read or write by owing to a certain flicker which seems common to all the regulators, but in warehouse or show-room use this does not cause any inconvenience, and we think in large places, especially those already having motive power, that it must eventually supersede gas.

Regent Street

H. J. NICOLL

\section{RELATION OF METEORITES TO COMETS:} II.

THERE are two classes of shooting stars which have been sometimes spoken of as unlike, but which are now admitted on all hands to be of common origin and character, namely, those which come in quantities on certain nights of the year, and give what is called a star shower, and the sporadic meteors, such as we can see on any clear night.

In November, 1799, von Humboldt saw during his travels in South America, a shower of shooting stars, and he has given a glowing description of the sight. These came on the morning of November 12. In 1832, November 13, there was seen in Europe a display of less brilliancy. It, however, attracted not a little atten-

I A lecture delivered in the Mechanics' Course at the Sheffield Scientifu School of Xale College, U.S., by Prof. H. A. Newton. Continued from p. 3 . 
tion, as descriptions and newspaper notices show in every country in Europe. But no person seems to have connected it with any previous shower, nor does it appear that any one gave a hint of the true nature of the phenomenon.

The next year there appeared in this country, on the morning of November 13 , a more brilliant shower, which some present doubtless witnessed. Through the morning hours of that day the stars shot across the sky like the flakes of snow in a snowstorm. Not a little difference was there in the way people looked at it. The negroes at the south thought the day of judgment had come. The owner of a plantation told me that his negroes had gathered in the "praise-house," and that he on being waked went down to quiet their fears. They had concluded not to call "Missus," as she would soon hear Gabriel's trumpet, and they well knew that she was ready to go. A student here in College was going to prayers, and saw a ball of light pass across the half lighted moving sky. He rubbed his eyes, thinking that something was the matter with them. A second flight made him sure that his eyes were troubled, and he looked down and hurried on to chapel. A servant girl by chance returning home in the early morning, saw it, but said nothing until it was talked of the next day. "Oh," said she, "I saw that." "Did you? Why did you not call us?" "Really, I didn't know but that the stars went out that way every morning." Prof. Twining saw it, and observing that all the flights were away from one point in the heavens, and that that point moved along with the stars as they rose in the morning sky, he said," These are not, as some say, meteorological phenomena; they are not, as others say, electric; these are bodies coming to us from beyond the air, and they belong to astronomy." This was the first definite proof of the cosmic origin of meteors.

Nine hundred and thirty-one years earlier, that is, in the year 902, there was a like brilliant shower of fire. A cruel Aghlabite king then reigned at Tunis. He had driven the Christians out of Sicily, penning up the Bishop of Taormina and the remnant of his people in the church, and burning it and them together. He had crossed to the mainland, and was besieging Cosenza, then an important city of Calabria. He suddenly died, and the flying monks were relieved of their terrors. They connected his death with the star-shower which occurred at or near the same time, and in all the annals it is repeated in varied phrases that on the night when King Ibrahim Bin Ahmad died an infinite number of stars scattered themselves like rain to the right and left.

Between the years 902 and 1799 the November meteors were seen in unusual numbers in at least nine different years. The showers in the table which I show you are not selected out of an indefinite number in our histories. On the contrary, they are nearly all which we have found in the records as having occurred near that time of year.

\begin{tabular}{|c|c|c|c|c|c|c|}
\hline $\begin{array}{l}\text { YEAR. } \\
902\end{array}$ & & & & & $\begin{array}{l}\text { Dax. } \\
\text { October }\end{array}$ & $\mathrm{I}_{3}$ \\
\hline $93 \mathrm{I}$ & $\cdots$ & $\cdots$ & $\cdots$ & $\cdots$ & , & 16 \\
\hline 934 & $\cdots$ & ... & $\ldots$ & ... & ", & I4 \\
\hline 1002 & $\cdots$ & $\cdots$ & $\cdots$ & $\cdots$ & ", & I5 \\
\hline IIOI & $\cdots$ & ... & $\cdots$ & $\cdots$ & , , & 17 \\
\hline I 202 & $\ldots$ & $\cdots$ & ... & $\cdots$ & , & 19 \\
\hline I 366 & $\cdots$ & $\cdots$ & $\ldots$ & $\cdots$ & $"$, & 23 \\
\hline I 533 & $\cdots$ & .. & $\cdots$ & $\cdots$ & ", & 25 \\
\hline 1602 & $\cdots$ & $\cdots$ & $\cdots$ & $\cdots$ & "' & 28 \\
\hline I698 & $\cdots$ & $\cdots$ & $\cdots$ & $\cdots$ & November & 9 \\
\hline I 799 & $\cdots$ & $\cdots$ & $\cdots$ & $\cdots$ & , & I2 \\
\hline 1832 & $\cdots$ & $\cdots$ & $\cdots$ & $\cdots$ & ", & r3 \\
\hline 1833 & $\cdots$ & $\cdots$ & $\cdots$ & $\cdots$ & , & 13 \\
\hline $1863-68$ & $\cdots$ & $\cdots$ & $\ldots$ & $\cdots$ & , & 14 \\
\hline
\end{tabular}

Notice now in this table that the showers came either near the beginning or near the end of the first third, or else near the end of the second third of the century. In other words, they all come near the end of a cycle whose length was $33 \frac{1}{4}$ years. Again, notice that the day of the month advanced with slight irregularity about three days in the century. The large advance of twelve days between 1602 and 1698 is due to the change of ten days in the reckoning in passing from old style to new style.

I have added, as you see, the six years from 1863 to

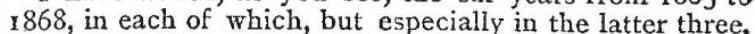
these meteors came, as we had expected, on the morning of Norember I4. They seemed in all these years to pass, as they did in $\mathrm{s} 833$, across the sky, as though going away from the constellation Leo, or rather from the sickle in Leo. This means that the small bodies really came into the air in parallel lines, the apparent radiation being the way in which parallel lines appear to us. There can be no doubt that there was the same parallelism of paths in all the earlier star-showers.

Here we have a group of solid bodies coming into the air all moving in one given direction. They come to us only on a particular time in the year, for the slow change from the middle of October to the middle of November can be explained. They come to us only at intervals of about a third of a century. These facts can only be satisfied by supposing that vast numbers of these small bodies are moving in a long thin stream around the sun, and that the earth, at the proper times, plunges through them taking into the air each time some scores of millions of them. Each of them must be moving in an orbit having the same period as every other, and approximately the same path.

Now it may be shown that there are but five orbits about the sun that can meet these conditions. Further than that, there is but one of these five that can explain the change of date from the middle of October to the middle of November, and this fifth one does explain the change perfectly. I cannot in the time you kindly grant me give in such detail that you can clearly understand them, the reasons for thus limiting the path of the meteoroids first to five possible orbits, and then to one of these five. I must ask you to accept the statement in view of the fact that no astronomer has, so far as I know, ever questioned the proofs of it.

That orbit is one which is described in $33 \frac{1}{4}$ years. The meteoroids go out a little further than the planet Uranus, or about twenty times as far as the earth is from the sun. While they all describe nearly the same orbit they are not. collected in one compact group. On the contrary they take four or five years to pass a given place in the orbit, and are to be thought of as a train several hundred millions of miles long, but only a few thousands of miles in thickness.

Now right along with this train of meteoroids travels a comet. It passed the place where we meet the meteoroid stream nearly a year before the great shower of 1866 , and two or three years before the quite considerable displays of 1867 and I 868 . It was therefore well towards the front in the great procession.

How came it that this comet and the meteoroids thus travel the same road-the comet with the meteroids and the meteoroids with each other? The plane of the comet's orbit might have cut the earth's orbit to correspond with any other day of the year than November 15. Or cutting it at this place the comet might have gone nearer to the sun or farther away. Or, satisfying these two conditions, it might have made any angle from zero to $180^{\circ}$ instead of $167^{\circ}$. Or, satisfying all these, it might have had any other periodic time than $33 \frac{1}{4}$ years; even then it might have gone off in any other direction of the plane than that in which the meteoroids were traveling. All these things did not happen by chance; there is something common.

The comet which I have named is not the only one that has an orbit common with meteoroids, though it is the only case in which the orbit of the meteoroids is 
completely known aside from our knowledge of that of the comet. Every August, about the tenth day, we have an unusual number of meteors-a star-sprinkle, as it has been called. A comet whose period is about 125 years moves in the plane, and probably in a like orbit with these meteoroids.

So near the first of December we have had several star-showers-notably one in 1872 - and these meteoroids are travelling nearly in the orbit of Biela's comet. In April, too, some showers have occurred which are thought to have had something to do with a known comet.

Thus much as to the meteors of the star-showers. The sporadic meteors are with good reason presumed to be (and observed facts prove some of them to be) the outliers of a large number of meteoroid streams, and the leading problem of meteor-science to-day is to find these streams so faintly shown, and, if possible, the comets they belong to.

Come back with me to the November stream and its comet. The several bodies move along a common path not at all by reason of a present physical connection. They are too far apart, in general a thousand times too far apart, to act on each other so much that we can measure the effect. No; their connection has been in the past. They must have had some common history.

Looking now at the comets, we see that they have been apparently growing smaller at successive returns. Halley's comet was much brighter in its earlier than in its later approaches to the sun. Biela's comet has divided into two, if not more than two, principal parts, and seems to have entirely gone to pieces. It could not be found in 1872, when and where it ought to have been visible. Several comets have had double or multiple nuclei. In the year 1366 , in the week after the star-shower, a comet crossed the sky exactly in the track of the meteors. A second comet followed in the same path the week after. Both belonged no doubt to the November stream, and one of them may perhaps have been the comet of 1866 .

This stream of meteoroids is a long thin one. In miniature it would be perhaps a mile long to an inch in thickness. We have crossed the stream at many places along a length of a thousand millions of miles, sometimes in advance of, and sometimes behind, the comet, and all along this length have found fragments, sometimes few, sometimes many. This form of the stream suggests continuous action producing it. A brief violent action might give this form, but a slowly acting cause seems more natural.

Again, in the history of Biela's comet we have distinct evidence of continued action. The comet divided into two parts not long before 1845 , and yet in 1798 fragments of it were met with so far from the comet, that they must have left the comet long before, probably many centuries ago.

Thus are we led to say, first, that the periodic meteors of November, of August, of April, \&c., are caused by solid fragments of certain known or unknown comets coming into our air; secondly, that the sporadic meteors such as we can see any clear night are the like fragments of other comets; thirdly, that the large fireballs are only larger fragments of the same kind; and finally, that this stone, which was broken off from one of those large fragments in coming through the air, must once have been a part of a comet.

Here I should naturally close, yet I am sure that you will ask, How came the comet to break up? Perhaps the prior question would be, How came the comet together? In its history there is much that we cannot yet explain, much about which we can only speculate. Thus, how came this stone to have its curious interior structure? As a mineral it resembles more the deepest firerocks than it does the outer crust of our earth. It seems to have been formed in some large mass, possibly in one larger than any of our existing comets. Some facts show that the comets have almost surely come to us from the stellar spaces. Out somewhere in the cold of space a condensing mass furnished heat for the making of this stone. The surrounding atmosphere was unlike ours, since some of these minerals could hardly have been made in the presence of the oxygen of our air. Either in cooling, or by some catastrophe, the rocky mass may have broken to pieces, so as to enter the solar system, having little or no cohesion, like a mass of pebbles; or, it may have come and probably did come, a single solid stone. In either case, as it got near to the sun, new and strong forces acted on it. The same heat and repulsion that develops and drives off from a comet in one direction a tail, sometimes a hundred millions of miles long, may have cracked off and scattered in another direction solid fragments. One of these contained in it this stone, and it wandered in its own orbit about the sun, itself an infinitesimal comet, how many thousands or millions of years we know not, until three years ago it came crashing through the air to the earth in lowa. Thence this fragment came here to serve as a text to my discourse.

METEOROLOGICAL STATION ON BEN NEVIS

WE are glad to learn that the Scotch Meteorological Society's scheme of a station on Ben Nevis is evoking cordial support from those who have the administration of Government funds available for such objects. The London Meteorological Council, of which Prof. Henry Smith is chairman, has unanimously agreed to offer to the Scotch Society $100 l$. yearly towards the support of the station, provided a copy of the observations is sent regularly to London. This is at once testimony by the most competent judges to the importance of the scheme, and a proper encouragement to the Scotch Society to proceed in its spirited enterprise. We understand that to uphold the station and induce two competent observers to take it by turns to live on the top of the mountain with an assistant will cost about $300 l$. yearly. It is estimated that to purchase a full stock of instruments and erect a building for them and the observers a capital sum of $800 \%$. will be required. The Scotch Society has applied for a grant of $400 l$. towards this expenditure from the Committee appointed by Government to distribute $4,000 l$. annually to encourage scientific research. We believe the Committee has not yet met to consider the various claims which are, no doubt, as usual made on the funds.

\section{RESEARCH UNDER DIFFICULTIES}

THE following short preface to a very valuable account of the stages of development from the egg of one of the centipedes (Geophilus), no member of which group had been studied previously to this account, gives so convincing a picture of the enthusiasm for investigation which may animate the modern naturalist, that it is worthy of a place in NATURE for the encouragement of the "craft." Elias Metschnik off has during the past fifteen years worked more assiduously with the microscope at the observation of the minute details of embryology than any other student. To him we are indebted for our first accurate knowledge of this subject in the case of many important animal forms, e.g., sponges, various jelly-fishes, marine worms, the scorpion, and the book-scorpions, various insects, crustaceans, starfishes, and ascidians. One result has been the injury of his eyesight. In reading to-day his memoir on Geophilus, published in 1875 (Zeitschr. fiir wiss. Zoologie), it occurred to me that the following passage has more than technical interest:-

"After having for many years sought in vain for material suited for the investigation of the embryology of the centipedes, I chanced to obtain a quantity of the eggs of 